\title{
The Management of Diabetic Foot Ulcers Using the Wound Treatment Techniques of Modern Dressing: A Systematic Review
}

\section{Mohamad Roni Alfaqih, Gabriel Wanda Sinawang, Rohmatul Faizah, and Andrik Hermanto}

Faculty of Nursing, Universitas Airlangga, Surabaya, Indonesia

\begin{abstract}
Background: One of the complications caused by diabetes mellitus is the problem of diabetic foot ulcers (DFU). The management of the DFU problem can be carried out through the wound care focused on the foot using modern dressings. This research was to determine the effectiveness of modern dressings on the healing process of diabetic foot ulcers.

Method: The methods used in arranging this systematic review were (1) the identification of interventions in the literature, (2) the identification of relevant literature based on the topic and title, (3) obtaining the literature in full-text form and (4) the analysis of the results from the various interventions in the literature. The literature search was carried out in several databases such as Scopus, Google Scholar and Pubmed. The samples in this article wee research about the effect of modern dressings in the treatment of diabetic foot ulcers.

Result: A total of 22 evidence bases found 10 studies using the preexperimental method, 3 RCTs, 2 quasi-experiments, 2 articles / systematic reviews, 2 perspective studies, 1 medical report, 1 case study and 1 vitro and vivo study.

Conclusion: Based on the review, it explains that the research on modern dressings using nanocrystalline silver ion and curcumin can improves wound recovery by increasing the transformation rate of the $B 1$ growth factor, which is a protein involved in cell growth and proliferation.
\end{abstract}

\section{ARTICLE HISTORY}

Received: Dec 26, 2019

Accepted: Dec 31, 2019

\section{KEYWORDS}

diabetic foot ulcer; wound; treatment; modern dressing; healing process

\section{CONTACT}

Mohamad Roni Alfaqih

$\triangle$ Mohamad.roni.al-

2018@fkp.unair.ac.id

$\fallingdotseq$ Faculty of Nursing, Universitas

Airlangga, Surabaya, Indonesia

Cite this as: Alfaqih, M. R, Sinawang, G.W, Faziah, R, \& Hermanto, A. (2019). The Management of Diabetic Foot Ulcers Using the Wound Treatment Techniques of Modern Dressing: A Systematic Review. Jurnal Ners, 14(3si), 176-180. doi:http://dx.doi.org/10.20473/jn.v14i3(si).17016

\section{INTRODUCTION}

Diabetes mellitus can be defined as a metabolic disorder in the human body. This metabolic disorder is caused by a lack of insulin production. The insulin deficiency in diabetes mellitus patients can be caused by excessive glucose in the bloodstream or the low production of insulin(Tavakkoli-kakhki \& Motavasselian, 2017).

Patients with diabetes mellitus have reached 150 million in the world today. It is estimated that by 2025 , there will be a two fold increase in the number of patients currently (World Health Organization, 2017). In Indonesia, the survey results of the number of people with diabetes mellitus reached approximately 12 million people with a proportion of 6.9\% (KemenkesRI, 2014). The complications of diabetes mellitus are grouped into 2, namely microvascular and macrovascular complications. One of the complications caused by diabetes mellitus is diabetic foot ulcers (DFU) which includes into microvascular complications(Nasiri et al., 2015). The latest method in managing DFU is by designing new wound care techniques. The principle use for wound care is managing the moist wound condition. (Liu, Zhou, Gao, \& Zhai, 2018). If the moisture of the wound is managed properly, then it will speed up the healing process. The area of the wound will be easily diminished and it will not easily get infected. The management of the DFU problem can be conducted via treatments using modern dressings (Tavakkolikakhki \& Motavasselian, 2017). Modern dressings are effective at accelerating the wound healing process.. 


\section{MATERIALS AND METHODS}

This systematic review was compiled with the aim of identifying the effect of modern dressing therapy on diabetes mellitus wounds. The methods used in arranging the systematic review was (1) the identification of the interventions in the literature, (2) the identification of the relevant literature based on the topic and title, (3) obtaining the literature in a fulltext form and (4) the analysis of the results from the various interventions in the literature.

The literature search was carried out on several databases such as Scopus, Google Scholar, Pubmed and so on by including the keywords of 'modern dressing', 'wound care management', 'diabetes mellitus', 'diabetic foot ulcers' and 'wound care treatments'. The year limit used was in the last 10 years, with the diabetic foot ulcer inclusion criteria according to a Randomized Controlled Trial Study (RCTs). The review included cluster RCTs, a quasiexperimental design, pre-experiment, case studies, systematic reviews and medical records. There was no age and gender limitation for the participants in the article.

The sample in this article consisted of 23 articles about the effect of modern dressing treatments on diabetic foot ulcers. The analysis was focused on modern dressing therapy with various combinations of interventions for diabetic foot ulcers patients and the side effects of the interventions. The criteria were excluded if the results of the study did not explain the effect of the modern dressing on the wounded patients. The instruments used were observation sheets, standard operating procedures (SOP) and the laboratory test results of the diabetic mellitus ulcers.

\section{RESULTS}

The sources obtained from the 15 studies focused on modern dressing therapy for diabetic foot ulcers is found 10 studies with experimental methods, 1 quasiexperimental, 1 article / systematic review, 1 medical report, 1 case study and 1 vitro and vivo study. There were several comparative interventions as described in Table 1.

\section{DISCUSSION}

Natural polymers have better biocompatibility such as lower immune degradation and resistance while synthetic polyesters have easier electrospinning with excellent mechanical strength such as flexibility and rigidity. To obtain the maximum benefit of these ingredients, it is highly recommended to use a mixed strategy. Bixin-load PCL nanofibers reduce the length of time of wound closure more than the PCL nanofibers. Other natural curcumin compounds derived from turmeric have many biological activities that have been proven such as anti-tumor, antioxidant, and anti-inflammatory(Liu et al., 2018).

Nanocrystalline silver ion, curcumin, improves wound recovery by increasing the transformation rate of the $ß 1$ growth factor, which is a protein involved in cell growth and proliferation (Shaikh et al. 2009). Moreover, these compounds also protect the skin cells from oxidative damage. Skin histological studies for the test group (with phylum curcumin) show that the area of hair follicles and sebaceous glands in the dermis layer of the skin is protected(Tong et al., 2018).

Nanocrystalline silver ion is an effective antimicrobial barrier consisting of a core to maintain an optimal moist environment for wound healing. Moreover, the outer layer of a silver dressing polyethylene net prevents wound contamination and has a bactericidal effect. Silver ions show faster wound contractions due to the accelerated proliferation and differentiation of fibroblasts to myofibroblasts(Gupta, Kakkar, Gill, Gill, \& Gupta, 2018). Silver gauze oil, when the bandage is exposed to the wound exudate, means that the silver ions are released immediately, binding and effectively killing the bacteria (Dong \& Liu, 2017).

Topical olive oil consists of $98 \%$ triglycerides, including oleatmonounsaturated acid, whose antiinflammatory properties have been completely and crucially proven for skin care as these properties are similar to ibuprofen (the current study links it to Oleocanthal). It possibly accelerates recovery and the healing process of the ulcer. Furthermore, because of the high concentration of polyphenols, the natural antioxidants included in the olive oil medicate the inflammatory process and increase blood flow so then they help with ulcer healing(Nasiri et al., 2015).

There is also the topical application of bee honey. Propolis has an antibacterial effect that has been proven in this study. The bacterial load (CFU) in propolis-treated ulcers decreased by $26 \%$ in terms of the diabetic wound fluid after 10 days compared with b $1 \%$ in the published control subgroup. Our laboratory study found that the number of growing bacteria predicts poor wound healing in a neuropathic ulceration, which is the dominant type of ulcer in this study (Xu et al., 2007)(Tavakkoli-kakhki \& Motavasselian, 2017).

Sucrose octasulfate and sulfate ligosaccharide are known to have many biological activities, particularly the potassium salts of sucrose octasulfate, which have been shown to inhibit the matrix of metalloproteases 22 . It also interacts with the growth factors and restores their biological functions since they have a high charge density (Edmonds et al., 2017). Fr Integra Flowable Wound, the use of biomaterials in expert hands and in selected patients allows for the rapid natural healing of lesions and it also allows for the reduction of major amputations caused by complications in more distal amputations in the lower limbs (F. Campitiello et al, 2017)

The development of wound healing in diabetes mellitus patients with a variety of simple alternatives can be used by both health workers and the patients as an effort to treat and prevent the complications of DFU. The choice of intervention can be adjusted according to the available health facilities and services in the surrounding environment. 
Table 1. Study of the Systematic Review Production

\begin{tabular}{ll}
\hline \multicolumn{1}{c}{ Author } & \multicolumn{1}{c}{ Type of stud } \\
\hline $\begin{array}{l}\text { (Liu et al., } \\
\text { 2018)(Liu et al., }\end{array}$ & Article review \\
2018) & \\
& \\
(Nasiri et al., & Quasi- \\
2015)(Nasiri et al., & experimental \\
2015) &
\end{tabular}

(Tavakkoli-kakhki Case study and Motavasselian, 2017)(Tavakkoli-

kakhki \&

Motavasselian, 2017)

(Henshaw et al., Prospektive 2014)(Henshaw et study al., 2014)

(Tsang et al., 2015) (Tsang et al., 2015)
Experimental

1.

Electrospun nanofibers as a wound dressing to treat diabetic foot ulcers

1. Topical Olive oil for wound healing in DM

2. Treatment of wounds in accordance with the protocol

3. Ulcer wound healing in Diabetes Mellitus type 2

1. The success of improving diabetic foot ulcers with honey-based treatment

1. Tolerance of topical applications from a honeycomb

2. Improved healing of diabetic foot ulcers

1. The anti-inflammatory effect of Nanocrystalline Silver and Manuka Honey.

2. The anti-bacterial effects of Nanocrystalline Silver and Manuka Honey.

\author{
(Dong and Liu, \\ 2017)(Dong \& Liu, \\ 2017) \\ (Edmonds et al., Experimental: \\ 2017)(Edmonds et double blind \\ al., 2017) \\ Experimental
}

\section{(F. Campitiello et al, 2017)}

(Ramarao and Ramu, 2017)(Ramarao \& Ramu, 2017)

1) Group 1: silver ion,

2) Group 2: oil gauze silver

3) Wound healing process

1) Intervention group: gauze with sucrose octasulfate

2) Control group: gauze without sucrose octasulfate

(Jung, Yoo and Han, Medical record 2016)(Jung, Yoo, \&

Han, 2016)

(Xu et al., 2018)(Xu, Min, Guo, Liao, \& Fu, 2018)
Experimental: simple random sampling Experimental: simple random sampling

1) Intervention group: Integra Flowable Wound Matrix

2) Control group: controlled dressing

1) Intervention group: nanocrystalline ionic silver dressing

2) Control group: daily dressing by giving gauze soaked in $\mathrm{NaCl}$

1) Intervention group: hydrophilic polyurethane dressing

2) Saline dressing

Experimental: random sampling
1) EFG (Epidermal Grow Factor) Group

2) aFGF (acidic fibroblast growth factor)

3) Combination of EFG and Afgf

4) Normal saline
Honey-based treatment is good for wound healing. The wound will be diminished from the wide area of the wound and it also becomes antibacterial so then it can prevent infection, especially in diabetic foot ulcers.

Topical propolis is a therapy which increases the wound covering in diabetic foot ulcers.

The findings from the in vitro and animal studies show that both agents have effective antibacterial actions. The anti-inflammatory actions and the impact related to the wound healing are not clear. Overall, the high-quality clinical human study is supported by the findings from molecular science concerning the lack of use of Manuka Honey or Nanocrystalline Silver.

Wound healing using oil gauze silver was faster than using silver ions.

Wound surface healing was faster in the intervention group than in the control group which reached 20 weeks. The life quality of both groups was bad.

1) The average duration of wound healing in the Integra Flowable Wound Matrix group was faster. The wound healing for the nanocrystalline silver ion dressing needed less time.

Total wound healing occurred in 87 patients (polyurethane dressing group) and in 28 patients in the control group within 12 weeks.

New tissue granulation at grades 2 and 3 needed less treatment time than in the combination group. 


\begin{tabular}{|c|c|c|c|}
\hline Author & Type of study & Variable & Result \\
\hline $\begin{array}{l}\text { (Niederauer, } \\
\text { Michalek and } \\
\text { Armstrong, } \\
\text { 2017)(Niederauer, } \\
\text { Michalek, \& } \\
\text { Armstrong, 2017) }\end{array}$ & $\begin{array}{l}\text { Analysis of a } \\
\text { randomized, } \\
\text { balanced, } \\
\text { double blind, } \\
\text { sham- } \\
\text { controlled, } \\
\text { parallel } \\
\text { group clinical } \\
\text { trial } \\
\text { evaluating } \\
\text { the use of the } \\
\text { CDO device } \\
\text { for DFUs }\end{array}$ & $\begin{array}{l}\text { Continuous diffusion oxygen (CDO) } \\
\text { therapy }\end{array}$ & $\begin{array}{l}\text { This research showed that oxygen } \\
\text { continuously spreading on the wound } \\
\text { significantly caused a higher and faster } \\
\text { level of wound closure. }\end{array}$ \\
\hline $\begin{array}{l}\text { (Tong et al., } \\
\text { 2018)(Tong et al., } \\
\text { 2018) }\end{array}$ & $\begin{array}{l}\text { In vitro and } \\
\text { in vivo }\end{array}$ & $\begin{array}{l}\text { The efficiency of nanocrystal cellulose } \\
\text { film as an anti-microbe medication } \\
\text { system in diabetic wound dressing. }\end{array}$ & $\begin{array}{l}\text { Film-charged curcuma significantly } \\
\text { improved the hairfollicles and sebaceous } \\
\text { skin glands. This result showed that } \\
\text { curcuma nanocrystal film could be used } \\
\text { for the application of diabetic wound } \\
\text { healing. }\end{array}$ \\
\hline $\begin{array}{l}\text { (Ramarao and } \\
\text { Ramu, } \\
\text { 2017)(Ramarao \& } \\
\text { Ramu, 2017) }\end{array}$ & Experimental & $\begin{array}{l}\text { 1) Group A (n: } 30) \text { used } 1 \text { cc of } \\
\text { Normal Saline and } 10 \text { IU of } \\
\text { insulin for every } 10 \mathrm{~cm} 2 \text { of } \\
\text { wound. } \\
\text { 2) Group B (n:30) used normal } \\
\text { saline for the wound treatment. }\end{array}$ & $\begin{array}{l}\text { Insulin topical dressing gave } \\
\text { advantageous results for the patients } \\
\text { with a diabetic foot ulcer. There was a } \\
\text { significant decrease on the wound's } \\
\text { surface compared to the normal saline } \\
\text { dressing. }\end{array}$ \\
\hline $\begin{array}{l}\text { (Rahayu et al., } \\
\text { 2018)(Rahayu, } \\
\text { Ramlan, Anwar, } \\
\text { Sri, \& Pujiastuti, } \\
\text { 2018) }\end{array}$ & Experimental & $\begin{array}{l}\text { 1. Control group received the } \\
\text { intervention with modern } \\
\text { antibacterials (calcium Alginate, } \\
\text { Cutimed Sorbact, Aquacel, } \\
\text { Dalethyne, and Iodosorb powder) } \\
\text { 2. Intervention group received the } \\
\text { same wound treatment using } \\
\text { modern antibacterial and ozone } \\
\text { therapy with } 60.100 \mu \mathrm{g} / \mathrm{ml} \\
\text { concentration for } 15 \text { minutes. }\end{array}$ & $\begin{array}{l}\text { Calcium Alginate lowered the wound's } \\
\text { size better than the other dressing. }\end{array}$ \\
\hline
\end{tabular}

\section{CONCLUSION}

Research on modern dressings has been abundantly done but of the results obtained, only a few have provided benefits related to the healing of diabetic foot ulcers. Some provide benefits as antibiotics that can reduce infection and others provide benefits that can accelerate reducing the wound area, maintaining the moisture and reducing the duration of the wound healing process.

\section{REFERENCES}

Dong, C. Y., \& Liu, W. J. (2017). Effect of oil gauze silver dressings on diabetic foot ulcers in the elderly. (October).

Edmonds, M., Lázaro-martínez, J. L., Alfayate-garcía, J. M., Martini, J., Petit, J., Rayman, G., \& Lobmann, R. (2017). Articles Sucrose octasulfate dressing versus control dressing in patients with neuroischaemic diabetic foot ulcers ( Explorer ): an international, multicentre, double-blind, randomised, controlled trial. 8587(17), 1-11. https://doi.org/10.1016/S2213-8587(17)304382

Gupta, V., Kakkar, G., Gill, A. S., Gill, C. S., \& Gupta, M. (2018). Comparative Study of Nanocrystalline Silver Ion Dressings with Normal Saline Dressings in Diabetic Foot Ulcers. Journal of Clinical and Diagnostic Research, (June 2017), 1-4. https://doi.org/10.7860/JCDR/2018/36691.115 90

Henshaw, F. R., Bolton, T., Nube, V., Hood, A., Veldhoen, D., Pfrunder, L., ... Twigg, S. M. (2014). Journal of Diabetes and Its Complications Topical application of the bee hive protectant propolis is well tolerated and improves human diabetic foot ulcer healing in a prospective feasibility study. Journal of Diabetes and Its Complications, 28(6), 850-857. https://doi.org/10.1016/j.jdiacomp.2014.07.012

Jung, J., Yoo, K., \& Han, S. (2016). Evaluation of the Efficacy of Highly Hydrophilic Polyurethane Foam Dressing in Treating a Diabetic Foot Ulcer. 29(12), 546-555.

KemenkesRI. (2014). Pusat Data dan Informasi.

Liu, Y., Zhou, S., Gao, Y., \& Zhai, Y. (2018). Electrospun nanofibers as a wound dressing for treating diabetic foot ulcer tr. Asian Journal of Pharmaceutical Sciences, 000, 1-14. https://doi.org/10.1016/j.ajps.2018.04.004

Nasiri, M., Fayazi, S., Jahani, S., Yazdanpanah, L., Haghighizadeh, M. H., \& Jundishapur, A. (2015). The effect of topical olive oil on the healing of foot ulcer in patients with type 2 diabetes: a doubleblind randomized clinical trial study in Iran. 
Niederauer, M. Q., Michalek, J. E., \& Armstrong, D. G. (2017). A Prospective, Randomized, Double-Blind Multicenter Study Comparing Continuous Diffusion of Oxygen Therapy to Sham Therapy in the Treatment of Diabetic Foot Ulcers. Journal of Diabetes Science and Technology, 11(5), 883-891. https://doi.org/10.1177/1932296817695574

Rahayu, U. M., Ramlan, D., Anwar, M. C., Sri, R. R., \& Pujiastuti, E. (2018). Combination of modern dressing and bagging ozone therapy for speed up the process of wound healing of grade II diabetic ulcer patients. (November 2017), 1-5.

Ramarao, K., \& Ramu, L. (2017). Comparative Study between the Effect of Topical Insulin and Normal Saline Dressing in Healing of Diabetic Foot Ulcers. 4(6), 1337-1339.

Tavakkoli-kakhki, M., \& Motavasselian, M. (2017). Successful Repair of Diabetic Foot Ulcer with Honey-Based Treatment: A Case Report. 19(3). https://doi.org/10.5812/ircmj.41939.Case
Tong, W. Y., bin Abdullah, A. Y. K., binti Rozman, N. A. S., bin Wahid, M. I. A., Hossain, M. S., Ring, L. C., ... Tan, W. N. (2018). Antimicrobial wound dressing film utilizing cellulose nanocrystal as drug delivery system for curcumin. Cellulose, Vol. 25, pp. 631-638. https://doi.org/10.1007/s10570017-1562-9

Tsang, K., Kwong, E. W., Woo, K. Y., To, T. S., Chung, J. W., \& Wong, T. K. (2015). The Anti-Inflammatory and Antibacterial Action of Nanocrystalline Silver and Manuka Honey on the Molecular Alternation of Diabetic Foot Ulcer: A Comprehensive Literature Review. 2015.

World Health Organization. (2017). Media Centre WHO Diabetes Mellitus.

Xu, J., Min, D., Guo, G., Liao, X., \& Fu, Z. (2018). Experimental study of epidermal growth factor and acidic fibroblast growth factor in the treatment of diabetic foot wounds. 5365-5370. https://doi.org/10.3892/etm.2018.6131 